\title{
POLÍTICA AGRÁRIA BRASILEIRA PÓS 64 E SUA RELAÇÃO COM A REDUÇÃO DO TRABALHADOR RURAL À CONDIÇÃO ANÁLOGA À DE ESCRAVO
}

\author{
Luiz Augusto Silva Ventura do Nascimento ${ }^{1}$
}

\begin{abstract}
Resumo: O presente estudo objetiva mapear, a partir de 1964, como a falta de uma política agrária nacional direcionada à distribuição de terras e com condições de propiciar autonomia ao trabalhador rural contribuiu para a formação de um contingente suscetível à exploração do trabalho rural em condição análoga à de escravidão presente até os dias atuais. Trata-se de pesquisa qualitativa com base em revisão bibliográfica sociológica e política para a construção de uma análise crítica. Por fim, conclui-se que as ações do Estado pró-ativo da modernização contribuíram para impedir a melhoria da condição de vida do homem do campo e para empobrecê-lo e sujeitá-lo ao trabalho em condições análogas à de escravo. Não houve planejamento social ou viabilização de condições para autonomia e independência do trabalhador rural - falta de acesso à terra.
\end{abstract}

Palavras-chaves: Trabalho em condições análogas à de escravo - política agrária reforma agrária - Estado.

\begin{abstract}
The present study has as objective to map how the lack of agrarian reform, a national land policy directed to land distribution and conditions of providing autonomy to rural workers after 1964 influenced the formation of a contingent of workers susceptible to exploration of rural labour in condition analogous to slavery - labour analogous slavery. It is a qualitative research method based on sociological and political literature review to construct a critical analysis. Finally, it is concluded that the actions of the proactive State of modernization created obstacles in the improvement of rural workers living conditions, impoverished them and submitted them to slave-like conditions. There was no social planning or conditions facilitation in order to provide autonomy and independence of rural workers - lack of access to land.
\end{abstract}

Keywords: Labour analogous slavery - agrarian policy - agrarian reform - State.

\section{INTRODUÇÃO}

Com o presente estudo visa-se descrever criticamente a política pública agrária brasileira a partir de 1964 e demonstrar como a busca desenfreada da modernização com a incorporação de tecnologias e formas modernas de armazenamento e comercialização contribuiu para a formação

Mestrando do Programa de Pós-graduação em Ciências Sociais da Universidade Estadual de Londrina (UEL). Orientador: Profa. Dra. Maria José de Rezende. E-mail: Isventura1@hotmail.com 
de um contingente de trabalhadores suscetível à exploração das relações de trabalho no campo em condição análoga à de escravidão devido ao empobrecimento do trabalhador rural.

$\mathrm{O}$ trabalho em condições equiparadas à de escravo existe em virtude da perda da dignidade humana do trabalhador nas relações sociais de produção. E mais, a perda da dignidade humana submete o indivíduo ao trabalho forçado, à jornada exaustiva e a condições degradantes. Podem ocorrer situações nas quais o empregador ou seu preposto restrinja a locomoção por meios físicos, por coação moral ou psicológica, tornando-o devedor, mediante contrato fraudulento de trabalho.

Nesse contexto, é oportuno registrar que a baixa instrução escolar, a grande concentração de terras nas mãos de grandes latifundiários, a lógica da produção agrícola e o modelo de desenvolvimento imposto na modernização do país são fatores que contribuem para o processo de miserabilidade do trabalhador rural, reduzindo-o à condição análoga à de escravo e à extrema miséria. Este estudo restringe-se a apontar as ações do Estado como reforço dessa situação.

Utilizou-se a pesquisa qualitativa, com base em revisão bibliográfica sociológica e política para a construção de uma análise crítica.

\section{O TRABALHO EM CONDIÇÕES ANÁLOGAS À DE ESCRAVO}

O artigo $2^{\circ}$ da Convenção n. 29, de 10 de junho de 1930, da OIT, define como forçado ou obrigatório todo trabalho ou serviço exigido de uma pessoa, para o qual ela não se tenha oferecido espontaneamente e isso sob ameaça de sanção e com cerceamento da liberdade. E a Convenção n. 105, de 5 de junho de 1957, da OIT, estabelece que o trabalho forçado jamais pode ser utilizado para fins de desenvolvimento econômico ou como instrumento de educação política, discriminação, disciplinamento, como punição por participar de greve. Esses documentos foram ratificados pelo Brasil, o primeiro em 1957 e o segundo em 1965 (OIT, 2011, p. 25-26).

Cabe esclarecer que as definições convencionais são complementares, sendo a primeira genérica com dois elementos centrais: punição e consentimento, incorporando-se as mais diversas formas coercitivas de controle da força de trabalho, sem que haja restrições quanto a regionalismos, a economias e à imposição estatal ou pública, e a segunda reflexo do momento histórico, pós-Segunda Guerra Mundial (1939-1945), proíbe o trabalho forçado em casos específicos conectados a circunstâncias econômicas e políticas (OIT, 2010, p. 36-38). 
Em relação a isso, Ricardo Rezende Figueira explana:

Como não se trata exatamente da modalidade de escravidão que havia na Antiguidade greco-romana, ou da escravidão moderna de povos africanos nas Américas, em geral o termo escravidão veio acrescido de alguma complementação: "semi”; "branca", "contemporânea", "por dívida", ou, no meio jurídico e governamental, com certa regularidade se utilizou o termo "análoga”, que é a forma como o artigo 149 do Código Penal Brasileiro (CPB) designa a relação. Também têm sido utilizadas outras categorias para designar o mesmo fenômeno, como "trabalho forçado", que é uma categoria mais ampla e envolve diversas modalidades de trabalhos involuntários, inclusive o escravo (FIGUEIRA, 2004, p. 33-35).

A Coordenadoria Nacional de Combate ao Trabalho Escravo CONAETE ${ }^{2}$ deliberou duas orientações, a n. 03 da jornada exaustiva e a n. 04 das condições degradantes de trabalho. A primeira orientação refere-se a conjunturas em que há prejuízos à saúde física ou mental do trabalhador, $\mathrm{e}$ à agressão à sua dignidade, decorrentes da situação de sujeição que, por qualquer razão, torne irrelevante a sua vontade. A outra define:

Condições degradantes de trabalho são as que configuram desprezo à dignidade da pessoa humana, pelo descumprimento dos direitos fundamentais do trabalhador, em especial os referentes a higiene, saúde, segurança, moradia, repouso, alimentação ou outros relacionados a direitos da personalidade, decorrentes de situação de sujeição que, por qualquer razão, torne irrelevante a vontade do trabalhador (BRASIL, 2012b, p. 10).

São utilizadas como sinônimas as expressões "escravidão contemporânea" e "formas contemporâneas de escravidão", porém, existem críticas quanto ao uso da locução "trabalho escravo", porque, sendo inexistente a escravidão no ordenamento jurídico-positivo, não há como conceber que alguém possa ser colocado na situação de escravo, o que ocorre, de fato, é a situação análoga à do escravo (BRITO FILHO, 2005, p. 78-90; GARCIA, 2008, p. 141-145; NEVES, 2003 p. 8-10).

Examina-se, outrossim, a definição presente na legislação nacional, com base na tipificação criminal do artigo 149 do Código Penal Brasileiro - o trabalho análogo ao de escravo é compreendido como:

“[...] o Ministério Público do Trabalho criou em 12 de setembro de 2002, por meio da portaria 231/2002 a atualmente denominada Coordenadoria Nacional de Erradicação do Trabalho Escravo. Antes da Coordenadoria, existiu no âmbito do MPT [Ministério Público do Trabalho] Comissão que desenvolveu estudos sobre estratégias de combate ao trabalho escravo e regula- 
Art. 149. Reduzir alguém a condição análoga à de escravo, quer submetendo-o a trabalhos forçados ou a jornada exaustiva, quer sujeitando-o a condições degradantes de trabalho, quer restringindo, por qualquer meio, sua locomoção em razão de dívida contraída com o empregador ou preposto: (Redação dada pela Lei $n$. 10.803, de 11.12.2003) Pena - reclusão, de dois a oito anos, e multa, além da pena correspondente à violência. (BRASIL, 1940).

Ressalte-se que, conquanto seja de 1940 o Código Penal brasileiro, a letra do artigo supracitado foi alterada, somente, pela Lei n. 10.803, de 11 de dezembro de 2003. Antes não havia qualquer especificação do significado do ilícito penal, o que tornava sua aplicação muito mais difícil ao caso concreto, em razão de cada magistrado interpretar subjetivamente o que era a "condição análoga à de escravo" no antigo texto legal, (BRASIL, 1940).

Para melhor esclarecimento, poder-se-ia utilizar o sintagma "violência à liberdade pessoal", mas seria preciso esclarecer que tal violência é a que reduz o trabalhador rural à condição de escravo. Assim, a redução era fática e não legal, porque inexistia uma definição normativa das circunstâncias que expliquem o que seja condição de escravizado.

Após a nova redação legal, a definição normativa ficou bem mais precisa. Configura-se a conduta quando o ser humano é submetido ao trabalho forçado, à jornada exaustiva, a condições degradantes de trabalho ou ocorra restrição à locomoção por causa de dívida para com empregador ou preposto; a modalidade servidão por divida pressupõe coação: física, psicológica e moral, para a permanência até a liquidação de débitos a que o trabalhador foi submetido por meios ou imposições contratuais fraudulentas.

LIGAÇÃO ENTRE A POLÍTICA AGRÁRIA E REDUÇÃO DO TRABALHADOR À CONDIÇÃO ANÁLOGA À DE ESCRAVO: LUTA DE INTERESSES

No início do governo Jânio Quadros (1961), instituiu-se uma comissão, sob o comando do senador Milton Campos, para avaliar a execução de uma política fundiária nacional voltada para mudança das políticas existentes e a extensão dos direitos trabalhista ao trabalhador rural. $\mathrm{O}$ resultado do trabalho foi uma das bases para elaboração do que resultaria no Estatuto da Terra. ${ }^{3}$ No entanto, como o Congresso Nacional era reduto

rização do trabalho indígena. Esta comissão foi criada em 5 de junho de 2001 e foi substituída pela Coordenadoria" (BRASIL, 2012b, p. 3).

3 Estatuto da Terra, Lei ${ }^{\circ} 4.504$, de 30 de novembro de 1964. 
dos interesses dos ruralistas, com representatividade mais expressiva que dos industriais, não houve espaço para a discussão, ficando os projetos da reforma agrária imobilizados ou bloqueados nas comissões técnicas e, quando colocados em votação eram derrotados (MEDEIROS, 1989, p.62).

É oportuno um parêntese para apontar que essa conjuntura de superestrutura, determinada pela infraestrutura, ainda não foi superada na sociedade brasileira. Basta analisar as amarras postas à Proposta de Emenda à Constituição (PEC) n. 438 de 2001, ${ }^{4}$ conhecida como PEC do Trabalho Escravo, que prevê a expropriação de terras de proprietários que, reconhecidamente, utilizem trabalho escrava.

Apesar de todos os esforços, a PEC vinha enfrentando forte resistência na Câmara dos Deputados desde 2004. Em 22 de maio de 2012, o texto foi aprovado, em segundo turno, pelo Plenário da Câmara dos Deputados. Devido à inclusão dos imóveis urbanos fez-se necessário retorno ao Senado Federal para nova votação (BRASIL, 2012c).

Em 19 de junho de 2013, quando estava prestes a ser votada, os senadores Sérgio Souza (PMDB-PR) e Blairo Maggi (PR-MT), integrantes da Frente Parlamentar da Agropecuária, da bancada ruralista, pediram vistas à proposta, o que causou o adiamento da votação. Ainda, sob a alegação de insegurança jurídica da bancada ruralista, o relator do projeto de lei, o senador Romero Jucá (PMDB-RR), em atendimento ao pedido dos defensores da grande propriedade, usou um conceito mais restrito de trabalho escravo, fixando uma definição bem aquém da do artigo 149 do Código Penal (SAKAMOTO, 2013), o que limitará a atuação do Poder Judiciário nos processos de desapropriação por exploração de trabalho escravo contemporâneo se aprovada a PEC. Portanto, mesmo aprovada, em 27 de maio de 2014 no Senado Federal, existe, ainda, o problema de se garantir o conceito legal do Código Penal na sua regulamentação. Têm-se projetos no Congresso Nacional para alterar o conceito vigente. Podem prevalecer os interesses da propriedade rural ao invés dos interesses do trabalhador rural.

\section{O GRANDE MEDO DA POLÍTICA AGRÁRIA}

Em 11 de outubro de 1962, no governo de João Goulart (19611964) foi fundada a Superintendência de Política Agrária (SUPRA),

“as propriedades rurais e urbanas de qualquer região do país onde forem localizadas culturas ilegais de plantas psicotrópicas ou a exploração de trabalho escravo serão expropriadas e destinadas à reforma agrária e a programas de habitação popular, sem qualquer indenização ao proprietário e sem prejuízo de outras sanções previstas em lei, observando, no que couber, o disposto no 
por meio da Lei Delegada de n.11, para a formulação da política agrária nacional: planejar, promover, executar e fazer executar a reforma agrária no país (BRASIL, 1962). "O Congresso Nacional permanecia impermeável a ela [reforma agrária]" (MEDEIROS, 1989, p. 63).

Em 14 de março de 1964, o presidente João Goulart assinou o decreto da SUPRA que declarou de interesse social para fins de desapropriação as áreas rurais que ladeiam os eixos ferroviários federais, os leitos das ferrovias nacionais e as terras beneficiadas ou recuperadas por investimentos exclusivos da União, em obras de irrigação, drenagem e açudagem, inexploradas contrariamente à função social da propriedade (DIÁRIO CARIOCA, 1964, p. 5). Outras medidas da reforma de base e a tentativa de solucionar a questão agrária nacional eclodiram no golpe políticomilitar de março de 1964 cuja força de sustentação foi a grande propriedade rural:

Quando o Estado brasileiro teve a possibilidade de encontrar uma solução para o caráter singular dos nossos problemas sociais, transformou-se em ditadura, justamente para evitar a solução, aliás mal encaminhada, formulada por aqueles setores mais politizados, na verdade da classe média, que falavam em nome dos pobres e dos trabalhadores. Como é o próprio, aliás, de nossas tradições políticas, mesmo da pequena e modesta tradição de esquerda que temos. Foram vários os fatores da ditadura. Mas, basicamente, o regime autoritário foi-nos imposto para evitar uma reforma social, sobretudo no direito de propriedade, que reconhece que o modelo agrário da Lei de Terras de 1850 estava vencido. (MARTINS, 2003, p. 173).

Devido às reformas propostas e à organização dos trabalhadores, ocorreram reações imediatas dos proprietários de terras em diversas esferas sociais visto que esses detinham o poder local, e controlavam as decisões judiciais em desfavor dos trabalhadores. Nas propriedades rurais, a reação foi de imposição de uma ordem (i) legal autônoma, da lei dos proprietários e de perseguições, de todo tipo, aos que contrariassem suas ordens. Ação dos jagunços no cumprimento das decisões que podiam ser de queima das casas dos "rebeldes", gados soltos nas lavouras, despejos e inclusive assassinatos (MEDEIROS, 1989, p.64).

$\mathrm{Na}$ esfera legislativa, os proprietários rurais eram amplamente representados pelo Partido Social Democrático (PSD) e União Democrática Nacional (UDN) e, portanto, com forças para impedir a aprovação de

Artigo $5^{\circ}$ da Constituição Federal”. Texto aprovado para a discussão que iniciou no Senado Federal - PEC n. 438 de 2001 (JUNGMANN, 2014). 
qualquer demanda que contrariasse seus interesses econômicos, tanto que, em relação à reforma agrária, foram capazes de articular amplas alianças com setores simpáticos de mudança na estrutura fundiária para que se alinhassem contra a emenda constitucional favorável à indenização da terra em títulos da dívida agrária. Por isso, o capital agrário valeu-se das associações municipais, federações estaduais e da Confederação Rural Brasileira, fundada no início da década de cinquenta para o enfrentamento político (MEDEIROS, 1989, p. 64).

Eles se configuravam como produtores que sustentavam a industrialização com as dívidas da produção sem estímulo do governo e, em razão disso, reivindicavam: políticas especiais de crédito, medidas de apoio à produção, construção de silos, armazéns, estradas, entre outras benesses que elevariam sua renda. Diziam que somente com o atendimento de seus pedidos poderiam melhorar as condições dos trabalhadores e evitar o êxodo rural. Também, cobravam ações do governo contra as tensões enfrentadas, já que apoiavam os bons trabalhadores de suas terras, e agora eram ameaçados por "forças externas" (MEDEIROS, 1989, p. 64-65).

Desta feita, pode-se verificar que os proprietários mostraram grande capacidade na construção de aliança política, com habilidade de coalizão e convencimento da fração industrial de que a reforma agrária não interessava de modo algum ao capital, argumentando que a estrutura estatal não suportaria reformas no formato da propriedade rural, muito menos concessões de direitos trabalhistas aos trabalhadores do campo (MEDEIROS, 1989, p. 64-65).

Portanto, ainda que houvesse empenho político em favor da mudança no arcabouço legal por parte do presidente João Goulart, a instauração de uma política fundiária para reparação das desigualdades criadas pela estrutura sociopolítica e jurídica implantada, desde então, no país acabou derrotada.

\section{O REGIME MILITAR E POLÍTICA AGRÁRIA}

É importante anotar que a ditadura militar (1964-1984), embora seja vista como tendo um único poder atuante representado pela corporação do exército, não se trata de uma ação singular. Havia um conjunto de forças políticas, econômicas e sociais, internas e externas que atuaram nesse período marcado por uma pretensão de legitimidade que ultrapassa os objetivos da simples obediência para uma complexidade que objetiva, de maneira contínua, que todos concordem, objetiva e subjetivamente, com a forma de organização social estabelecida (REZENDE, 2001, p. 31). 
A autuação estatal é autoritária e marcada por um modelo nacional de estado desenvolvimentista caracterizado pelo alinhamento da economia nacional ao padrão de desenvolvimento capitalista, em vigor na década de sessenta e setenta. No campo, objetivava-se "a reestruturação da base produtiva da agropecuária brasileira integrando-a ao complexo agroindustrial de insumos e maquinarias agrícolas e à indústria de transformação de alimentos e fibras" (SORJ; WILKINSON, 2008, p. 270-271).

Para atingir esses objetivos, por meio de um Estado ativo, são estabelecidas novas estruturas político-ideológicas e econômicas de dominação as quais continuam a favorecer os grandes proprietários.

Nesse rumo, atendo-se à questão agrária, impõe-se apontar as reformas políticas do governo Castello Branco (1964-1967) cujo objetivo era a racionalização da organização e dos métodos do trabalho da máquina burocrática para redirecionar o Estado rumo à modernização com a deterioração dos mecanismos tradicionais de dominação do campo. $\mathrm{O}$ modelo de estado desenvolvimentista do regime ditatorial almejava, a qualquer custo, o rompimento com o atrasado, o anacrônico, com aquele subdesenvolvimento caracterizado pelo latifúndio escravocrata e autoritário. Acreditavase que o moderno era a única forma de romper com a estrutura política da desigualdade (BALTAR, 2009, p. 90).

A Emenda Constitucional n. 10 de 10 de novembro de 1964, permitia a desapropriação para fins de reforma agrária com indenização em títulos da dívida pública (SILVA, 1987, p. 17).

Em 30 de novembro de 1964, o Estatuto da Terra, Lei n. 4.504, foi sancionado. $\mathrm{O}$ governo considerava-o uma lei de desenvolvimento rural; porém, com duas características contraditórias: reforma agrária e desenvolvimento. Os imóveis rurais eram classificados em minifúndios, latifúndios por exploração, latifúndios por dimensão e empresas rurais. Objetivava-se a extinção, paulatina, das fontes de conflitos, os minifúndios e latifúndios. A empresa seria o modelo ideal de propriedade fundiária. A exploração era "econômica e racional". A legislação viabilizaria o cumprimento da função social que a Constituição de 1946 impunha com a manutenção dos níveis de produtividade, permitindo o desenvolvimento industrial e garantindo relações de trabalho "justas". Nesta oportunidade, extinguiase a SUPRA e criavam-se dois novos órgãos: o IBRA (Instituto Brasileiro de Reforma Agrária), subordinado, diretamente, à Presidência da República, e o INDA (Instituto Nacional de Desenvolvimento Agrário), ligado ao Ministério da Agricultura. Era a composição do aparato institucional necessário à promoção de transformações das relações no campo (MEDEIROS, 1989, p.86). 
Com a reformulação da estrutura fundiária, o governo objetivava impedir uma luta política dos trabalhadores do campo pela reforma agrária. Uma forma de esvaziar a política do campo com a despolitização da luta pela terra - obstáculo que impedia tornar-se a luta uma luta política ou político-partidária favorável aos rurícolas. Era um modo de favorecer a manutenção do regime militar e o projeto desenvolvimentista do Estado (MARTINS, 1984, p. 56).

A grande modernização transformou as relações sociais de produção porque alterou o ciclo natural do cultivo e mudou a utilização da força de trabalho no campo. Em suma, tem-se, no processo de produção automatizado, mais um agravante que marca as necessidades desiguais entre o capital empresarial agrícola e a força de trabalho.

Dito de outro modo, a expulsão do produtor causada pela entrada do maquinário ou a geração de força de trabalho homogênea pela mecanização depende do produto e dos níveis de concentração e mecanização. Porém, de modo geral, pode-se afirmar quê, com a implantação tecnológica, houve redução da força de trabalho na agricultura (SORJ; WILKINSON, 2008, p. 268-269).

Esse foi o resultado da intervenção massiva do Estado na integração da grande propriedade na estrutura da produção agroindustrial que se realizou por meio da criação ou redirecionamento de superintendências.

A Superintendência de Desenvolvimento da Amazônia (SUDAM) foi criada em substituição à antiga Superintendência do Plano de Valorização Econômica da Amazônia (SPVEA) criada em 1953 por Getúlio Varga, com a Lei n. 5.173, de 27 de outubro de 1966 (BRASIL, 2012a, p. 2).

Com a sanção presidencial da Lei n. 5.174, de 27 de outubro de 1966, são introduzidas políticas públicas de incentivo financeiro e fiscais para a ocupação de novas áreas, em especial na Amazônia, por investidores privados, nacionais e internacionais. A legislação previa isenção de impostos de renda, taxas federais a atividades industriais, agrícolas, pecuárias e de serviços básicos, bem como de impostos e taxas para importação de máquinas e equipamentos para bens doados por entidades estrangeiras. Essa política contribuiu para o aumento da acumulação de capital pelas frações capitalistas, comercial e industrial, envolvendo a cadeia produtiva agrícola ou pecuária.

No mesmo rumo, foram as ações governamentais em relação ao Nordeste e ao cerrado brasileiro, com a Superintendência do Desenvolvimento do Nordeste (SUDENE) e Programa para o Desenvolvimento dos Cerrados (POLOCENTRO). 
A SUDENE, criada e idealizada no governo Juscelino Kubitschek (1956-1961) como parte do programa desenvolvimentista para servir de incentivos financeiro e fiscal como a SUDAM, foi desvirtuada do seu objetivo inicial que era a diminuição das desigualdades entre as regiões geoeconômicas.

O POLOCENTRO, nas regiões dos cerrados, introduzido em 1975, buscou a transformação da agricultura de subsistência em uma agricultura empresarial por meio da utilização de práticas agrícolas tecnológicas e a integração com o mercado. A autuação do governo está em prover ampla assistência técnica, apoio financeiro e de infraestrutura ao agronegócio.

Frise-se que o Decreto n. 59.456, de 4 de novembro de 1966, instituiu o primeiro Plano Nacional de Reforma Agrária que não ultrapassou a letra da lei; todavia, merece ser ressaltado que, com fulcro no conceito de imposto territorial progressivo, propunha-se uma iniciativa de reforma agrária que consistia na eliminação dos proprietários incapazes de modernizar suas propriedades rurais; facultou-se, do mesmo modo, o surgimento de uma nova pequena-burguesia rural, autônoma e competitiva que coexistiu com os médios e grandes capitais (CRUZ; MARTINS, 2008, p. 18).

Além disso, em 19 de dezembro de 1966, com o Decreto-Lei n. 79, Política de Garantia de Preços (PGPM), o governo federal passou a intervir no mercado agrícola para fixar preços mínimos e executar operações de financiamento e aquisição de produtos agropecuários para garantir a renda produtiva, por meio de empréstimos ou compra: o Estado assume o risco econômico do negócio, uma vez que sustenta os preços na entressafra. Mecanismo inviável no Brasil devido à ocorrência de assimetria entre os índices de preço utilizados para correção do salário mínimo e a efetiva variação dos preços no mercado (SANTOS, 1996, p. 102).

Essas políticas de facilidade ao acesso à propriedade de terras e incentivos fiscais, em curto prazo, acelerou a ocupação das regiões por grandes empresas e grupos econômicos, bem como o barateamento da força de trabalho e empobrecimento das populações rurais. E mais, contribuiu fortemente para a concentração de terras e a violência no campo, aviltando-se os conflitos fundiários e, consequentemente, a exploração do trabalho em condições análogas à de escravo (BRASIL, 2012a, p.2):

\footnotetext{
O início dos anos 60 foi marcado pela intensificação dos conflitos no campo, que se estenderam inclusive por regiões onde até então não tinham tido maior expressão. Se o clima em que o país vivia, de debate sobre a necessidade de reformas profundas, entre elas a agrária, para acelerar o processo de desenvolvimento, teve
} 
um peso na emergência de novos conflitos, não há como negar também que a
existência de resistências bem sucedidas levou a que, em algumas regiões, não se
aceitasse mais passivamente uma ordem de expulsão, salários baixos, aumentos das
taxas de arrendamento etc. Ao mesmo tempo, a violência dos proprietários de
terra, que não era fato novo na história do país, tornou-se mais dirigida, voltando-
se contra algumas lideranças expressivas. [...] Embora em alguns locais os confli-
tos ganhassem maior destaque, acentuadamente o caso do Nordeste, pelo impacto
das Ligas Camponesas, a questão agrária, com diferentes facetas, aparecia num
enfrentamento mais generalizado entre trabalhadores e proprietários, colocando
em jogo a disputa pela terra, a luta por direitos trabalhistas e a liberdade de
organização (MEDEIROS, 1989, p.66).

Convém registrar que a guerrilha do Araguaia esteve fortemente direcionada à política fundiária em prol dos pequenos produtores e dos posseiros da Amazônia repercutindo significativamente em ações do Estado para desapropriação de terras por interesse social para fins de reforma agrária. Entretanto, em 1973, antes do seu fim, o governo reorienta sua política fundiária direcionando-a para a grande empresa, agropecuária ou de colonização. Assim, pequenos produtores do sul vendem suas terras para comprar propriedades maiores na Amazônia, favorecendo a empresa privada de colonização. Para o governo federal era uma forma de conciliar segurança, desenvolvimento e desativação de áreas de tensão (MARTINS, 1984, p. 52).

Além disso, a combinação do ambiente de violência no campo com a consolidação do Estado autoritário e a necessidade de liquidação dos movimentos sociais fez com que houvesse uma sindicalização rural em massa durante o regime militar. Todavia, era uma sindicalização sem espaços para qualquer mobilização autônoma e de caráter de classe, não era raro encontrar a atividade de produtores familiares tanto nos sindicatos patronais quanto nos sindicatos dos trabalhadores (SORJ; WILKINSON, 2008, p. 271).

Desta forma, no governo Castello Branco (1964-1967), a questão agrária aparece nitidamente como uma questão empresarial e econômica ao invés de um problema social. Os encaminhamentos dados se fazem sem qualquer enfrentamento ao direito de propriedade, as decisões eram pensadas como recursos para atenuar os focos de tensões, diminuir o êxodo rural e aumentar a produção de alimentos (MARTINS, 1984, p. 41).

Em 1968 e 1969, no governo de Costa e Silva (1967-1969), em decorrência de emperramentos na efetivação da reforma agrária e proble- 
mas de corrupção que evolvia funcionários do governo em questões agrárias houve intervenção militar no INBRA criado pelo Estatuto da Terra de 1964. Por isso, em setembro de 1968, foi criado o Grupo Especial de Reforma Agrária (GERA) cujo objetivo era detectar os obstáculos e efetivar a reforma agrária nacional sob o comando do ministro do interior, general Albuquerque Lima ${ }^{5}$, que considerava o problema da terra uma questão militar. Mas em janeiro de 1969, houve reforma ministerial e o coronel Costa Cavalcanti assumiu o Ministério do Interior. Atentando-se para a sua declaração "a reforma agrária vai manter a atual estrutura fundiária, pois a política do governo é de realizá-la sem a divisão de terras", feita em Porto Alegre, meses após assumir o Ministério do Interior, é possível concluir que a reforma agrária não seria feita (MARTINS, 1984, p. 41-42).

Esse período é marcado pela intensa repressão política. Em 25 de abril de 1969, promulgou-se o Ato Institucional n. 9 que dava poderes ao presidente para desapropriar terras sem prévia indenização, em casos de interesse social. Consequentemente, 72 horas depois do decreto presidencial, a terra poderia ser ocupada antes do ressarcimento (SILVA, 1987, p. 17; MARTINS, 1984, p. 39). Em seguida, houve o Decreto n. 554, 25 de abril de 1969, que estabelecia o rito sumário para as desapropriações por interesse social, para fins de reforma agrária (SILVA, 1987, p. 17).

Mais tarde, em 17 de abril de 1972, em resposta à situação de guerrilha estabelecida na região de Santa Terezinha entre jagunços e habitantes, institui-se o Decreto presidencial n. 70.430, com a imposição de audiência prévia do Ministério da Agricultura antes de qualquer desocupação forçada. Entretanto, os advogados que reivindicavam a aplicação do referido decreto eram fichados como comunistas pelo Conselho de Segurança Nacional (MARTINS, 1984, p. 22-23).

No governo Emílio Médici (1969-1973) embora as medidas favoráveis aparentassem ser aos trabalhadores sem terra, estava sendo, paulatinamente, suprimida a base institucional da reforma agrária (MARTINS, 1984, p. 44).

Em 16 de junho de 1970, o governo federal lançou o Plano de Integração Nacional (PIN), Decreto-Lei n. 1.106, que determinava a construção da Transamazônica e da Cuiabá-Santarém, um programa de irrigação no Nordeste e faixas de terras para colonização e reforma agrária (MARTINS, 1984, p. 45). Em seguida, com o Decreto-Lei n. 1.110, de

Para ele, a política de integração da Amazônia era objetivo nacional. A pressão social e fundiária do nordeste se resolveria com projetos de ocupação dos espaços da Amazônia, polos de desenvolvimento (MARTINS, 1984, p. 41-42). 
9 de julho de 1970, foi fundado o Instituto Nacional de Colonização e Reforma Agrária (INCRA), resultado da fusão do IBRA com o INDA. Nesse período, houve incentivo à colonização da região amazônica com intensa migração de trabalhadores de outros estados para as margens da estrada Transamazônica (INCRA, 2011).

A promoção da expansão econômica da Amazônia ocorreria de dois modos: com a "colonização" por população do nordeste e sul do país e investimento em grande escala por meio de incentivos econômicos e fiscais para projetos agropecuários (SUTTON, 1994, p. 23).

É mister transcrever o relato da pesquisadora Alison Sutton sobre os efeitos do abandono dos migrantes e os incentivos financeiros ao grande capital internacional e grandes empresas:

Os colonos muitas vezes foram entregues à própria sorte, tornando-se mais tarde mão-de-obra barata, ao passo que as grandes empresas tiraram proveito de reduções de impostos que podiam dar direito a abatimentos de até $50 \%$ de todo o imposto devido pela empresa, se o equivalente a mais de dois terços desse desconto fosse investido em projetos industriais ou agrícolas na Amazônia Lega. Entre as empresas que se beneficiaram das isenções de impostos e subsídios havia multinacionais - como Volkswagen, Nixdorf, Liquigás - e grupos bancários nacionais - como Bradesco, Banco Real e Bamerindus. Essas empresas subcontrataram um grande número de trabalhadores para desmatar as terras de suas fazendas. Houve denúncia de trabalho forçado contra algumas delas, mas não todas. (SUTTON, 1994, p.23)

Outro plano criado foi o Programa de Redistribuição de Terras e de Estímulo à Agroindústria do Norte e Nordeste (PROTERRA) de 6 de julho de 1971, com o objetivo central de criar o espaço para o trabalhador sem terra (MARTINS, 1984, p. 44), indenizando-se e desapropriando-se latifúndios para loteamento em pequenas e médias propriedades para venda; concessão de crédito para a compra de terras; fixação de preço mínimo para exportação de produtos. Havia previsão de concluir, em janeiro de 1974, "a entrega de trezentos títulos, de propriedades de terras, beneficiando 3.500 famílias da região" (PORTAL SÃO FRANCISCO, 2014, p.04).

O crescimento econômico (1969-1973), rápido e excepcional, foi alavancado pelo Programa de Ação Econômica do Governo (PAEG) implantado em 1964. Esse Programa acelerou a urbanização e industrialização, sem qualquer alteração no formato da propriedade rural. Aguar- 
dou-se, porém, muito tempo para dividir o bolo ${ }^{6}$ que já havia crescido; mas ele não foi distribuído. A riqueza continuou concentrada com crescimento das desigualdades sociais e da pobreza generalizada:

[...] o processo de modernização agravou a concentração da riqueza e renda já existente, acentuando-a na fase de industrialização substitutiva. Somente o segmento de população que controla o setor de produção afetado pelos aumentos de produtividade - aumentos permitidos pelas vantagens comparativas no comércio internacional e pela industrialização substitutiva - desfruta os benefícios da modernização [...] (FURTADO, 1992, p. 44).

Nos pequenos centros os trabalhadores expulsos do campo passavam a viver em barracas de lona. Nos grandes e médios, a miséria estava na periferia, em ocupações irregulares ou favelas, em moradias precárias, sem alimentação adequada, sem contrato de trabalho, sem segurança no transporte ou equipamento de proteção individual, e com jornadas exaustivas de até 12 horas. Os trabalhadores estavam expostos a todo tipo de doença como verminose e tuberculose, além dos acidentes de trabalho, carentes de direitos trabalhistas e sem qualquer direito previdenciário (SUTTON, 1994, p.159). Típica anomia na relação de trabalho que pode ser definida legalmente como trabalho escravo contemporâneo.

Desde o início do governo Emílio Médici (1969-1973) o ministro da agricultura, Cirne Lima, deixava claro sua posição favorável ao deslocamento populacional espontâneo para a Amazônia. Segundo o ministro, os critérios burocráticos, administrativos e empresariais não contemplavam qualquer distribuição ou redistribuição de terras aos agricultores em condições precárias. Em maio de 1973, o ministro "renunciou" ao cargo depois

6 “ Antônio Delfim Netto, economista formado pela USP em 1951, participou dos governos dos generais Castello Branco (19641967), no Conselho Consultivo de Planejamento (Consplan); Costa e Silva (1967-1969) e Medici (1969-1973), como ministro da Fazenda; e Figueiredo (1979-1984), como ministro da Agricultura e secretário do Planejamento, controlando, a partir da primeira metade de 1979, o Conselho Monetário Nacional e o Banco Central. No governo entre 1967-1973, com a expansão do comércio e a intensificação dos fluxos financeiros mundiais, adotou política de aumentar o gasto público e incentivar as empresas privadas e multinacionais a investirem na indústria - foram US\$2872 milhões em investimento estrangeiro direto no período e na infra-estrutura do país, reduzindo juros e ampliando crédito. O resultado, considerando o período de 1968 a 1973, foi crescimento do PIB (11,1\%), queda da inflação (19,2\%) e aumento do poder aquisitivo do empresariado e da classe média para consumir bens duráveis, em especial eletrodomésticos e automóveis $O$ período da sua gestão foi chamado 'milagre econômico', pela expansão dos negócios financeiros, construção de obras faraônicas ('projetos de impacto') [...]. O governo contraía empréstimos de bancos privados estrangeiros para contornar os déficits da balança de pagamentos, causados pelo valor das exportações de manufaturados ser menor que o da importação de bens de capital, o que praticamente triplicou a dívida externa brasileira de 1967 a 1972, quando ficou em US\$ 9,521 milhôes. Delfim afirmava querer 'fazer o bolo crescer, para depois dividi-lo', mas os benefícios econômicos não atingiram pessoas de baixa renda, que tiveram seus salários reduzidos e sua participação na renda nacional decrescida de mais de 1/6 em 1960 para menos de 1/7 em 1970.” (FOLHA DE SÃO PAULO, 2008). 
de denunciar que a agricultura estava pagando o lucro das multinacionais por causa da política de preços que lesava o interesse dos agricultores (MARTINS, 1984, p. 44-46).

Em 11 de dezembro de 1973, com a Lei n. 5.969, o governo criou o Programa de Garantia da Atividade Agropecuária (PROAGRO) cujo objetivo consistia em exonerar o produtor rural do cumprimento de obrigações financeiras ou indenizar o valor investido em caso de ocorrência de perdas das receitas esperadas devido a causas naturais; objetivava também impulsionar a utilização de tecnologia propícia às atividades desenvolvidas e apoiar os meios de produção mobilizados por empreendimento, com orientações e assistência técnica (SANTOS, 1996, p. 102).

O PROAGRO se dividiu em dois. O primeiro iniciou no Branco Central do Brasil sendo sua administração transferida em 1988 para o Tesouro Nacional, sob a responsabilidade do Ministério da Fazenda, sendo suas receitas e despesas inclusas no orçamento da União. Com duração desde janeiro de 1975 até agosto de 1991. O segundo foi criado com o Decreto n. 175, de 10 de julho de 1991, novamente gerido pelo Branco Central do Brasil custeado por recursos da União provenientes de contribuições do produtor rural - prêmio/adicional - e das aplicações do adicional. Em sua estrutura há possibilidades de deficit, já que os prêmios não são compatíveis com a margem de risco das lavouras seguradas (SANTOS, 1996, p. 102).

Em suma, os projetos implantados no regime militar (1964-1984), de certa forma, atendem os grandes proprietários, mas não apresentam uma política agrícola consistente com um projeto de nação capaz de satisfazer os interesses dos homens do campo, pequenos proprietários e trabalhadores rurais.

Então, em vez de democratizar a propriedade rural, os caminhos traçados pelo Estado ditatorial, em especial no momento conhecido como "milagre econômico" (1969-1973), impulsionaram o capitalismo com a promoção da modernização das grandes propriedades. Aliás, o dinheiro era farto e barato. A conjuntura estimulava o cultivo da soja, pois era preciso gerar grandes excedentes exportáveis, recorrendo-se para isso ao crédito rural fortemente subsidiado e abundante.

Constata-se que os trabalhadores sem terra, expulsos, com pouca terra ou ameaçados de expulsão, são obrigados a conviver com a forma geopolítica de centralização imposta pelo governo até 1973. Posteriormente, com o fim das operações militares em face da Guerrilha do Araguaia, o governo reorientou sua política fundiária com o favorecimento das grandes 
empresas, da agropecuária ou de colonização (MARTINS, 1984, p. 5052).

O governo Ernesto Geisel (1974-1979) é considerado como momento de distensão e crise econômica do regime ditatorial. Os conflitos disseminados no Sul, Sudeste e Nordeste multiplicam-se rapidamente na Amazônia principalmente devido à regulamentação de grilagem de terras em 1976. De acordo com dados da CPT, dos 715 conflitos cadastrados no país ocorridos entre janeiro de 1979 e julho de 1981 , 88, $1 \%$ tiveram início em 1973. Essa multiplicação dos conflitos obrigou o governo federal a desapropriar terras por interesse social, para fins de reforma agrária, contudo, fez isso em escala mínima (MARTINS, 1984, p.55).

O manifesto denominado de "o documento dos oito", do final de junho de 1978, foi elaborado por oito representantes da grande indústria nacional cujo teor substancial era manifestar a definição de democracia como "sistema superior de vida, mais apropriado para o desenvolvimento das potencialidades humanas" (REZENDE, 2001, p. 231).

Depois do Segundo Plano Nacional de Desenvolvimento (II PND), entre 1975 e 1979, a zona rural sofreu um processo de expansão das relações capitalistas por causa da implantação da indústria agrícola e da modernização tecnológica: o agronegócio.

Antônio Delfim Netto publicou um artigo na Folha de São Paulo, em 19 de agosto de 1979, como ministro do planejamento, orçamento e gestão, reafirmando que a solução para a crise econômica do momento era a constituição da grande empresa no campo e da modernização das atividades agrícolas (MARTINS, 1984, p. 54). É a passagem de política de povoamento e desenvolvimento para a política de desenvolvimento econômico e modernização.

Segundo Alison Sutton, a partir da década de setenta, houve a substituição dos cafezais pela cultura da soja, mecanizada e submetida aos padrões internacionais e em atendimento às demandas do mercado exterior. No estado do Paraná, dispensaram mais de 200 mil trabalhadores dos estabelecimentos médios e grandes, área total ou superior a cinquenta hectares. Esse processo de expulsão formou um contingente imenso de mão de obra não especializada, por isso, barata, situação que obrigou, e ainda obriga, trabalhadores a se sujeitar a condições precárias para sua subsistência (1994, p.159).

Inexistem números exatos, mas, conforme dados estimados da Secretaria da Agricultura do Estado do Paraná, o contingente populacional expulso foi de 300 a 400 mil pessoas. Contudo, a CPT do estado do 
Paraná avaliou que entre 800 mil e um milhão de trabalhadores saíram do campo para a cidade, incluindo crianças de até seis anos de idade, obrigadas a trabalhar com chupeta na boca para complementar a renda familiar (SUTTON, 1994, p.159).

Portanto, o modo de produção capitalista no campo, primordialmente, com a especialização do trabalho rural, com a racionalização, a mecanização e a submissão da força de trabalho pelo capital sem a capacitação dos trabalhadores expulsos contribuíram, fortemente, para sua escravização, tornando-se eles mão de obra barata sujeita às condições impostas pelo capital.

E nas décadas de sessenta e setenta que surgem as primeiras denúncias de utilização do trabalho escravo contemporâneo no Brasil, coincidindo com o já mencionado crescimento econômico e a expansão da fronteira agrícola sul pelos estados do Mato Grosso e Pará, bem como o anúncio da expansão econômica da região amazônica (SUTTON, 1994, p.23).

$\mathrm{Na}$ década de oitenta, ocorreu aquilo que José de Souza Martins denomina de "militarização da questão agrária". Em outras palavras, o Estado, com o objetivo de neutralizar as tensões no campo, tem uma forte atuação na questão agrária para: reprimir; intervir e regularizar as áreas de tensão e fazer propaganda de que realizaria a "maior reforma agrária do mundo" (MEDEIROS, 1989, p.157).

Conforme dados da CPT, entre 1964 e 1992, foram assassinados 1.782 camponeses, trabalhadores rurais, líderes sindicais, agentes de pastoral, padres e advogados, procuradores em disputas judiciais, agrárias e trabalhistas. Em 1993, somente 35 tinham sido julgados com somente 20 condenações (SUTTON, 1994, p. 27).

A repressão estatal se dava, de modo indireto, pela omissão do Estado diante das milícias privadas, grileiros e proprietários de terras ou, de modo direto, pela intervenção policial ou militar nos conflitos.

Ainda, vale lembrar a conivência jurídica ante as ações das milícias privadas, as quais objetivavam semear o medo e impedir qualquer forma de manifestação. As ações tiveram como alvo lideranças sindicais, advogados e agentes de pastoral.

Leonilde Sérvolo de Medeiros aponta uma importante informação sobre a atuação estatal. Ela coloca o Estado, por sua omissão, como agente excludente direto na formação do contingente suscetível à escravidão contemporânea: 
À medida que o Estado tornou-se um agente produtivo, também se constituiu um instrumento de expulsão de trabalhadores. O caso exemplar talvez seja o da construção de barragens, onde a lógica do "progresso econômico" implicou em despejos, indenizações irrisórias, repressão policial, enfim, um quadro que em nada se distingue da violência dos grandes proprietários e grileiros. (1989, p. 158).

Como a modernização dispensa mão de obra no campo, reduzindo a oferta de emprego e, consequentemente, provocando o empobrecimento de diversos segmentos sociais do setor agrícola: trabalhadores rurais, assalariados ou parceiros, e pequenos proprietários rurais. A situação difícil dos rurícolas poderia ser aliviada mediante uma melhor distribuição da renda, ainda que se desacelere o desenvolvimento econômico:

Através de um amplo programa de reforma agrária, mesmo num sentido restrito de parcelamento de terras dos estabelecimentos agrícolas, poder-se-ia chegar a uma melhor distribuição de renda e minorar, em parte, a pobreza das classes mais desfavorecidas. Entretanto, [...], há o inconveniente de a melhor distribuição de renda vir acompanhada de um longo retardamento do processo de modernização agrícola, com reflexos negativos sobre o aumento de produtividade e o próprio desenvolvimento econômico do País (PAIVA, 1979, p. 184-185).

É tão premente a questão da pobreza na agricultura com reflexos em grande parte da população que Ruy Miller Paiva, em sua discussão sobre o problema social, em publicação de 1979, propõe a criação de programas de natureza assistencial para, pelo menos minorar e não solucionar a situação de pobreza dos agricultores:

\footnotetext{
Através de programas de natureza assistencial poder-se-á minorar (e não resolver) o problema da pobreza na agricultura e permitir que a espera dessa enorme população do País por melhores condições de emprego e de renda no futuro se torne menos angustiosa [...] A ampliação da política assistencial às áreas atrasadas para a agricultura de baixa renda do País em geral exigirá volumosos recursos financeiros para que produza um impacto positivo nas condições brasileiras, devido á elevada percentagem de agricultores (pequenos proprietários e não proprietários) que subsistem em condições extremamente desfavoráveis de vida. [...] programas relacionados com melhorias em habitação, saúde, alimentação, etc., implica uma transferência ainda maior de renda das classes mais favorecidas, via Governo, para as mais pobres. Mas é o preço que se tem de pagar para manter o processo de desenvolvimento econômico e social do País (PAIVA, 1979, p. 185-186).
} 
A partir de 1980, marca-se a intervenção estatal com a criação do Grupo Executivo das Terras do Araguaia - Tocantins (GETA) sob a coordenação da Secretaria Geral do Conselho de Segurança Nacional, já que se agiria, principalmente, em situações tensas, de violência e conflitos, sendo necessários poderes para alienar os imóveis, reconhecer a posse, discriminar terras devolutas ocupadas ilegalmente, resolver projetos para obtenção de títulos ou licença para a ocupação (MARTINS, 1984, p.59). No mesmo sentido, criou-se o Grupo Executivo do Baixo Amazonas (GEBAM).

A repressão estatal consistiu no verdadeiro objetivo da criação desses órgãos, cujo objetivo não era executar uma reforma fundiária com desapropriação ou distribuição de terras públicas, mas neutralizar os movimentos de trabalhadores rurais e grupos indígenas inconformados com os projetos agropecuários, madeireiros e de extração mineral (MEDEIROS, 1989, p. 160).

Em 16 de agosto de 1982, criou-se o Ministério Extraordinário para Assuntos Fundiários pelo Decreto n. 87.457, criação justificada por considerar-se a questão agrária um problema nacional, tanto que o comando ficou com o general Danilo Venturini quem já era responsável pela Secretaria do Conselho de Segurança Nacional (SILVA, 1987, p.18).

Por ser progressiva a militarização agrária, o governo interveio com desapropriações. Contudo, deve-se esclarecer que as expropriações eram somente em áreas de extrema tensão como Alagamar, na Paraíba, e Ronda Alta, no Rio Grande do Sul, observando-se sempre o "princípio da conciliação", o que significava a pedido do proprietário e com indenização lucrativa.

Houve propaganda governamental com as ações de desapropriações e regulações fundiárias com as titulações. Era uma estratégia governamental para neutralizar a opinião pública em relação a algumas medidas, como ameaça de banimento ou expulsão de padres, responsabilização criminal dos dirigentes sindicais, como incursos nos crimes previstos na Lei de Segurança Nacional (BRASIL, 1983), assassinatos e perseguições de líderes sindicais e agentes de pastoral (MEDEIROS, 1989, p.161).

Em 1984, nas reivindicações do movimento "diretas já"7 e na defesa pública por uma política de reforma agrária, preparou-se o IV Congresso Nacional dos Trabalhadores Rurais promovido pela Confederação Nacional dos Trabalhadores na Agricultura (CONTAG). Nessa ocasião, foram discutidos vários pleitos: a lei de greve, a ampliação dos direitos traba-

Movimento ocorrido entre 1983 e 1984 na sociedade civil cujo objetivo era reivindicar eleições diretas para o cargo político de presidente da República. 
lhistas e previdenciários, a política agrícola do governo, a necessidade de apoio econômico efetivo à pequena produção, a política de barragens entre outros. Três deles centraram o debate no movimento sindical: a reforma agrária, a ampliação de participação das bases no interior do sindicalismo e a discussão acerca da natureza da ação sindical (MEDEIROS, 1989, p.168).

Em 1985, o censo agrário do Instituto Brasileiro de Geografia e Estatística (IBGE) revelou a extrema concentração da propriedade de terras. Os dados compilados indicam que $90 \%$ das propriedades rurais tinham extensão inferior a cem hectares, mas ocupava-se apenas $21,2 \%$ de sua área física; A extensão de $0,93 \%$ delas era de mais de mil hectares, totalizando 43,8\% da área dos imóveis (SUTTON, 1994, p. 27).

Observando-se a evolução dos dados entre os anos de 2003 e 2010, com base nas estatísticas cadastrais do INCRA, verifica-se que existem 69.2 mil grandes propriedades improdutivas e passíveis de desapropriação, com área equivalente a 228.5 milhões de hectares. Muitas propriedades rurais são improdutivas, dado que poderia ser diferente se existisse uma política de redistribuição de terras. De acordo com os apontamentos do Movimento Humanos Direitos (MHuD):

[...] em relação ao ano de 2003, [...] [as] posições [...] [em] 2010 representaram incrementos de $18.7 \%$ no número de imóveis [improdutivos] e de $70.8 \%$ na área. Sintomaticamente, em que pese o maior crescimento de área das grandes improdutivas ter ocorrido no Norte do país (155.5\%), em termos de número de imóveis, o maior incremento ocorreu na região Sul do Brasil. Em 2003 havia naquela região 5.413 imóveis classificados como grandes improdutivas. Em 2010 esse número passou para 7.139 , o que correspondeu a uma expansão de $32 \%$ contra $30 \%$ no Norte. Há, no Sul, 5.3 milhões hectares de áreas improdutivas em grandes propriedades; em todas as regiões foi observado o crescimento do número de imóveis e áreas das grandes propriedades improdutivas. Por fim resta informar que das 130.5 mil grandes propriedades cadastradas em 2010, com área de 318.9 milhões hectares, 23.4 mil com área de 66.3 milhões de hectares não têm a propriedade reconhecida. Ou seja, são imóveis detidos a título precário, i.e, objeto de posse ou misto. Portanto, há um amplo território em todas as regiões do país para a execução da reforma agrária com obtenção via desapropriação, sem ameaçar a "eficiência" da grande exploração do agronegócio (MOVIMENTO HUMANOS DIREITOS, 2011).

O crédito, monopólio dos proprietários, acentua a concentração de 
renda e riqueza. À população despossuída continuava inacessível aos benefícios do crescimento econômico. Não havendo política de ruptura dessa distorção, quanto mais aumenta a produtividade mais crescia a injustiça social. $\mathrm{O}$ único bem de que os despossuídos dispunham era sua força de trabalho regulada pelo mercado para favorecer o baixo custo de reprodução, condição econômica de perpetuação da miséria (FURTADO, 1992, p.53).

A crise do petróleo de 1979 resultou no descontrole econômico e político do modelo de Estado desenvolvimentista da década de oitenta. Não foi possível manter os grandes investimentos estatais, o controle dos preços, pelas câmaras setoriais, e a captação de recursos junto ao Banco Nacional da Habitação (BNH) e à Previdência Social.

Devido à crise da dívida, crise do Estado e crise de legitimidade do regime ditatorial, houve o esgotamento do modelo de desenvolvimento centrado no Estado articulador e promotor da ordem econômica.

O Brasil moderno consistiu na polaridade: de um lado, a ordem social competitiva, e de outro, a regulação estatal. Todavia, o momento de crise ensejou novos arranjos políticos para retomada do equilíbrio econômico a partir do processo de (re)democratização pós-regime militar (BALTAR, 2009, p.90-91).

\section{CONSIDERAÇÕES FINAIS}

Pode-se perceber que as políticas públicas para a superação da condição periférica do Estado nacional centraram-se no desenvolvimentismo. A autuação ocorreu de maneira puramente econômica, com a industrialização e a viabilização de crescimento econômico. $O$ foco era criar condições para o crescimento do produto interno bruto (PIB) per capita e expansão do setor industrial - como indicadores "confiáveis" do grau de desenvolvimento de uma sociedade. Instituíram-se, então, políticas de incentivos financeiros e fiscais àqueles que tinham condições de impulsionar a economia, disponibilizando-se o dinheiro público (de todos) para incentivar o desenvolvimento do agronegócio.

As condições para a modernização, contudo, não eram universais, assim, os segmentos do setor social agrícola economicamente desfavorecido empobreceu, ficando no prejuízo trabalhadores, posseiros e agricultores impedidos financeiramente de se modernizarem.

Nos vinte anos entre a promulgação do Estatuto da Terra (1964) e o fim do regime militar (1984), inexistiu qualquer ação que pudesse 
minimizar as mazelas causadas pela burocracia no povoamento de certas regiões e desenvolvimento tecnológico no campo. Não houve qualquer política que pudesse auxiliar o pequeno agricultor para: investir em pesquisa em áreas favoráveis a produtos agrícolas; manter a agricultura tradicional em regiões menos favorecidas; propiciar incentivos fiscais e crédito agrícola; facilitar a irrigação em regiões de seca; garantir o preço dos produtos; uma política que implantasse reforma agrária para a desconcentração de terras.

Não se trata de ser contra o desenvolvimento e o crescimento do PIB per capita, mas é preciso que as políticas considerem a qualidade e a distribuição do crescimento entre todos que fazem parte do contrato social, com distribuição de renda, qualidade de vida, educação e sustentabilidade ambiental.

Um modelo desenvolvimentista deve refletir diretamente nas relações sociais, especialmente no âmbito do trabalho. Deste modo, é mister que o Estado invista em estudos para implantar uma política pública capaz de corrigir todas as distorções que a modernização pode gerar.

No caso do Brasil, as ações do Estado pró -ativo da industrialização e modernização trabalharam em desfavor do homem do campo. Não houve planejamento social nem se viabilizaram condições para a autonomia e independência do trabalhador rural - condições de acesso à terra. $\mathrm{O}$ mais grave de tudo, faltou competência para a execução de políticas distributivas.

A desorganizada modernização tecnológica no campo impulsionou o agronegócio, incentivando o êxodo rural sem qualquer possibilidade de incorporação do contingente de trabalhadores nas cidades. Os trabalhadores rurais se dirigiram às cidades e, sem qualificação para os serviços urbanos, tornaram-se uma massa de mão de obra barata, ou mesmo ociosa, sujeitando-se às condições desumanas impostas pelo capital agropecuário ou extrativista e ao trabalho escravo contemporâneo como meio de garantir a sobrevivência.

Ficam registradas a igualdade formal e a desigualdade real. Embora haja uma igualdade formal entre os seres humanos preconizada na legislação nacional, no plano material existe uma extrema desigualdade. Há trabalhadores que não têm seus direitos fundamentais resguardados, nem sequer o mais simples deles, a dignidade de pessoa humana, muito menos os direitos políticos de cidadão e os direitos trabalhistas.

É indispensável e forçosa uma política agrária competente que não só atinja o cerne das causas, a exclusão social, engendrada pela extrema pobreza, mas também proporcione, se bem que tardiamente, ao trabalhador o tão almejado acesso à propriedade rural para sua autonomia e, consequentemente, cidadania plena. 


\section{REFERÊNCIAS BIBLIOGRÁFICAS}

BALTAR, Ronaldo. A reconstrução do Discurso sobre o "Brasil Moderno" e a ideia de "desenvolvimento" pós-transição democrática. In: CHAIA, Vera Lúcia Michalany; MACHADO, Eliel. (Org.). Ciências Sociais na Atualidade: tempo e perspectiva. São Paulo: Paulus, 2009.

BRASIL. Código Penal - Decreto Lei n. ${ }^{\circ} 2$ 848, de 07 de dezembro de 1940.

. Presidência da República. Lei Delegada de n. ${ }^{\circ} 11$, de 11 de outubro de 1962. Disponível em: <www.planalto.gov.br/ccivil_03/leis/ldl/ldl11.htm>. Acesso em: 15 jan. 2014.

. Lei $\mathrm{n}^{\circ}$ 7.170, 14 dez. 1983. Disponível em: <www.planalto.gov.br/ccivil_03/leis/17170.htm>. Acesso em: 20 maio 2014.

. Ministério do Trabalho e Emprego. Trabalho Escravo no Brasil em Retrospectiva: Referências para estudos e pesquisas. jan. 2012a. Disponível em: <http://portal.mte.gov.br/data/files/ 8A7C816A350AC882013543FDF74540AB/retrospec_trab_escravo.pdf >. Acesso em: 15 jan. 2014.

. Ministério Público do Trabalho. $\mathrm{O}$ trabalho escravo está mais próximo do que você imagina. jan. 2012b. Disponível em: <http://portal.mpt.gov.br/wps/wcm/connect/9a0cf38047af3bb1bd98bfd0854ab81a/ Cartilha +Alterada_3-1.pdf?MOD=AJPERES\&CACHEID=9a0cf38047af3bb $1 \mathrm{bd} 98 \mathrm{bfd} 0854 \mathrm{ab} 81 \mathrm{a}>$. Acesso em: 15 jan. 2014.

. Ministério Público do Trabalho. Câmara dos deputados aprova a PEC do Trabalho Escravo. 23 maio 2012c. Disponível em: < http://portal.mpt.gov.br/wps/portal/portal_do_mpt/comunicacao/noticias/conteudo_noticia/!ut/p/c5/ 04_SB8K8xLLM9MSSzPy8xBz9CP0os_iAUAN3SydDRwOLMC8nA89QzzAnCldzQwNHA_lwkA4k> Acesso em: 15 jan. 2014.

BRITO FILHO, José Cláudio Monteiro de. Trabalho com redução do homem à condição análoga à de escravo e dignidade da pessoa humana. Revista do Ministério Público do Trabalho na Paraíba. Procuradoria Regional do Trabalho - 13 ${ }^{\text {a }}$ Região, João Pessoa, n. 1, p. 141-154, jun. 2005.

CANUTO, Antônio; LUZ, Cássia Regina da Silva; WICHINIESKI, Isolete. (Org.) Conflitos no campo Brasil 2009 - CPT. São Paulo: Expressão Popular, 2010.

CRUZ, Sebastião Carlos Velasco E; MARTINS, Carlos Estevam. De Castello a Figueiredo: uma incursão na pré-história da "abertura". In: ; ALMEIDA, Maria Hermínia Tavares de (Org.). Sociedade Política no Brasil pós-64. Rio de Janeiro: Centro Edelstein de Pesquisas Sociais, 2008. p. 0890.

DIÁRIO CARIOCA. Decreto da SUPRA. Rio de Janeiro, 14 mar. 1964. Disponível em: <http:// brasilrepublicano.com.br/fontes/9.pdf>. Acesso em: 20 maio 2014.

FIGUEIRA, Ricardo Rezende. Pisando fora da própria sombra. A escravidão por dívida no Brasil contemporâneo. Rio de Janeiro: Civilização Brasileira, 2004.

FOLHA DE SÃO PAULO. 1968 - ATO INSTITUCIONAL Nº 5. Os personagens: Antônio Delfim Netto 1.mai.1928 - Ministro da Fazenda. Biografia. 2008. Disponível em: <wwwl.folha.uol.com.br/ folha/treinamento/hotsites/ai5/personas/delfimNetto.html >. Acesso em: 20 maio 2014.

FURTADO, Celso. Brasil: a construção interrompida. 2. ed. Rio de Janeiro: Paz e Terra, 1992.

GARCIA, Gustavo Felipe Barbosa. Trabalho análogo à condição de escravo e degradante: antítese do trabalho decente. Suplemento Trabalhista, São Paulo, ano 44, n. 28/08, p. 141-145, 2008.

INCRA. Instituto Nacional de Colonização e Reforma Agrária. Histórico da questão agrária. $02 \mathrm{dez}$. 2011. Disponível em: <www.incra.gov.br/index.php/reforma-agraria-2/questao-agraria/historico-da-questaoagraria >. Acesso em: 20 maio 2014.

JUNGMANN, Mariana. PEC do Trabalho Escravo deve ser votada dia 27. EBC Agência Brasil. Brasília. 18 maio 2014. Política. Disponível em: <http://agenciabrasil.ebc.com.br/politica/noticia/ 2014-05/pec-do-trabalho-escravo-deve-ser-votada-dia-27>. Acesso em: 20 maio 2014. 
MARTINS, José de Souza. A militarização da questão agrária no Brasil. Petrópolis: Ed. Vozes, 1984. . A sociedade vista do abismo. 2. ed. Petrópolis: Ed. Vozes, 2003.

MEDEIROS, Leonilde Servolo de. História dos movimentos sociais no campo. Rio de Janeiro: FASE, 1989. Disponível em: <http://pt.scribd.com/doc/115011047/Historia-dos-movimentos-sociais-nocampo >. Acesso em: 20 maio 2014.

MOVIMENTO HUMANOS DIREITOS. (MHuD). Evolução da Concentração da Propriedade da Terra no Brasil: Evolução da Concentração da Propriedade da Terra no Brasil Medida pelos Imóveis 2003/2010. 22 jun. 2011. Disponível em: <www.humanosdireitos.org/noticias/denuncias/19-Evolucaoda-Concentracao-da-Propriedade-da-Terra-no-Brasil.htm >. Acesso em: 20 maio 2014.

NEVES, Robinson. Trabalho escravo: modificação do tipo penal. Revista Síntese de Direito Penal e Processual Penal, São Paulo, n.17, p. 8-10, jan. 2003.

OIT. Combatendo o trabalho escravo contemporâneo: o exemplo do Brasil, Brasília: OIT, 2010.

. Perfil dos principais atores envolvidos no trabalho escravo rural no Brasil, Brasília: OIT, 2011.

PAIVA, Ruy Miller. A agricultura no desenvolvimento econômico: suas limitações como fator dinâmico. Rio de Janeiro: IPEA/INPES, 1979.

PORTAL SÃO FRANCISCO. Governo general Médici. Disponível em: < www.portalsaofrancisco.com.br/ alfa/governo-medici/governo-medici-4.php>. Acesso em: 03 maio 2014.

REZENDE, Maria José de. A ditadura militar no Brasil: repressão e pretensão de legitimidade 1964 1984. Londrina: UEL, 2001.

SAKAMOTO, Leonardo. Prepara-se, no Senado, um golpe contra os trabalhadores. Repórter Brasil. 04 out. 2013. Disponível em: <www.trabalhoescravo.org.br/noticia/73>. Acesso em: 03 maio 2014.

SANTOS, Milton Luiz de Melo. Política Agrícola Brasileira - Uma breve análise retrospectiva e sua interrelação com a Política monetária. In: CAVALCANTI, José Euclides; AGUIAR, Danilo R. D. (Orgs). Política agrícola e desenvolvimento, Viçosa: UFG, 1996, p. 99-113.

SILVA, José Gomes da. Caindo por terra: crises da reforma agrária na nova república. São Paulo: Bisca Vida, 1987.

SORJ, Bernardo; WILKINSON, John. Processos sociais e formas de produção na agricultura brasileira. In: ; ALMEIDA, Maria Hermínia Tavares de (Orgs). Sociedade Política no Brasil pós-64. Rio de Janeiro: Centro Edelstein de Pesquisas Sociais, 2008. p. 245-278.

SUTTON, Alison. Trabalho escravo - um elo na cadeia da modernização no Brasil de hoje. São Paulo: Anti-Slavery International, Secretariado Nacional da Comissão Pastoral da Terra, 1994. 